\title{
Resolving Deep-Water Channel Architectures: High-Resolution Forward Seismic Modeling of Turbidite Systems, Ainsa II Channel, Campodarbe Group, Northern Spain
}

\section{TOC \\ Start}

Author

Search

Help

\section{Pringle, Jamie K.}

Present address:

School of Physical Sciences \& Geography

Keele University

Keele, Staffs. ST5 5BG, UK

Stanbrook, David A.

Present address:

Maersk Olie og Gas A/S,

Esplanaden 50

1098 København K

Denmark

e-mail: dast@maerskoil.com

\section{Clark, Julian D.}

Present address:

ChevronTexaco

6001 Bollinger Canyon Road

Building D-1180

San Ramon, California 94583, USA

\begin{abstract}
Turbidite channel systems are a common target in exploring for petroleum reservoirs though their internal architectures can be highly varied. To investigate channel architectures in turbidite systems, the spectacularlyexposed, Ainsa II channel in the Spanish Pyrenees is used to generate forward synthetic seismic 2D sections. Three parameters are varied independently: input model detail, seismic impedance contrast, and dominant wave-

let frequency. Representative seismic velocity and rock density values are taken from published reservoir data for observed lithologies. The three petroleum reservoir scenarios investigated are: a Plio-Pleistocene Gulf of Mexico reservoir and Tertiary and Jurassic UK North Sea reservoirs. Four Ricker wavelet dominant frequencies are chosen to generate the seismic models: 26,52 , 78 and $104 \mathrm{~Hz}$.
\end{abstract}


Results show that 2D synthetic seismic images generated from the low frequency wavelets $(26 \mathrm{~Hz})$ do not resolve the important heterogeneities within the channel complex. At $52 \mathrm{~Hz}$, frequencies that are typically used for the interpretation of shallow-level, Tertiary targets, an improved seismic resolution of the input model can be achieved, suggesting that the target interval consists of stacked channels, although not all channel units are resolved. At $78 \mathrm{~Hz}$, which is typical of

\section{Introduction}

Deep-water turbidite channels are of common interest in hydrocarbon exploration; however, internal architectures and overall net/gross can be hard to resolve in typical seismic datasets. Channel-fill may range from high net/gross, back-stepping sheet-like geometries, multiple channel re-incisions to mass-transport complexes, or passive infill. Seismic data are heavily relied upon for such interpretations but in reality may not adequately resolve these internal geometries. In these circumstances outcrop analogs can provide appropriate-scale examples of intra-channel geometric relationships and aid the understanding of what the seismic expression may be. Interpreting the complexity of this scale of sandstone architecture will be crucial in predicting fluid flow behavior in analogous subsurface reservoirs. Forward seismic modelings of large-scale, outcrop exposures have been created (see Batzle and Gardner, 2000; Coleman et al., 2000; high-frequency seismic acquisition and processing, an interpretation close to the input geological model can be achieved. At $104 \mathrm{~Hz}$, the excellent seismic resolution can be interpreted to reproduce the input model. The results also show that differing impedance contrast values have little effect on the geological interpretation at the high signal/noise ratios used, although impedance values from the UK North Sea Jurassic reservoir analog yield the highest amplitudes in the synthetic sections.

Schwab et al., 2007) to show geophysicists how much high-resolution outcrop data is imaged in seismic data of comparable reservoir intervals. The Ainsa II channel is one such seismic-scale outcrop exposure.

The Ainsa II channel within the Campodarbe Group in northern Spain is a spectacular exposure of slope conduits. The channel complex consists of five stacked channel units, is characterized by distinct internal architectures (documented by Clark, 1995), and can be usefully converted to a synthetic seismic section. The exposure has been field investigated, interpreted, digitized, and modeled to generate both typical and high-frequency seismic 2D sections, using typical reservoir lithology density and velocity values in order to investigate the effect that different rock properties and seismic frequencies have on seismic resolution of the geological detail in the channel complex. 


\section{Regional geological context}

The Eocene Hecho Group crops out in the southern area of the Central Pyrenees, and makes up a portion of the depositional fill of the Tremp-Pamplona basin; a foreland basin trending axially along the south side of the Pyrenees (Fig. 1). The Hecho Group type area is around Jaca (Fig.1), and is also equivalent to the Alveoline to Campodarbe Groups. A regional stratigraphic framework, based on unconformity-bounded stratal units, has been proposed by Mutti et al., 1989 (Fig. 2). The Upper Campodarbe Group is characterized by well developed, deep-water channel-levee complexes, typified as Type II or Type III systems (sensu Mutti and Normark, 1987). These turbidite systems are volumetrically less significant than the older Type I systems (ibid), which form extensive lobe deposits in the central sector of the basin. The Ainsa turbidite system has two main sandy channel-fill complexes: the

\section{The Ainsa II channel setting}

The Ainsa II channel is well studied within the Campodarbe Group (e.g., Clark, 1995; Pickering and Corregidor, 2000; Pringle et al, 2001, Larue et al, 2004; Schwab et al, 2007). The Eocene Campodarbe Group crops out in the southern part of the Central Pyrenees. In the central sector of the Tremp-Pamplona basin, near the town of Ainsa, the Campodarbe Group consists of fine-grained, submarine slope sediments (characterized lower Ainsa I and the upper Ainsa II channel complexes.

The main structural elements that can be seen on the paleogeographic map (Fig. 3) include east-west orientated thrusts (in the northern part of this area) and two major north-south orientated anticlines; the Boltaña and Mediano anticlines. Paleo-environmental studies show how the transition from shallow marine sandstones in the east to deep-water basin sediments in the west occurs via a mudstone-dominated slope environment incised with sandstone-filled canyons and channels. Large-scale erosional features of the shelfedge region are developed along the boundary between the eastern and central sectors of the basin as well as along part of the southern margin (Fig. 2). Prominent sand-rich channel-bodies are clearly visible and are colored in orange in Figure 3 with the white color being background shale intervals.

by mud-rich mass-failure deposits) and coarse-grained, deep-marine sand-rich channel and scour-fill deposits. One of the largest exposures of these slope conduits is the Ainsa II channel complex. The channel complex consists of five stacked channel units, each of which is characterized by a distinctive internal architecture (Clark, 1995). 


\section{Methodology}

Forward seismic modeling (also known as synthetic seismic) in this study involves the collation of outcrop data in the form of large-scale photomontages which are then interpreted by a geoscientist to produce a detailed, 2D architectural interpretation of the outcrop exposure (Fig. 4). The initial 2D interpretation is then validated by field ground-truth investigations and detailed sedimentary outcrop logs that also provide high-resolution, 1D data. The detailed architectural interpretation is then fed into special software that convolves the model into a seismic section, using user-

\section{Field correlation/interpretation}

A total of fourteen channel systems have been identified in the Ainsa basin (Clark, 1995) and are summarized in Figure 5. A study of the Ainsa II complex has made possible a detailed interpretation of the sedimentological aspects of the channel complex, both as a whole and as individual channels; the section is shown with five times vertical exaggeration in Figure 6 ( $c f$ Fig. 4). The dominant paleoflow is northwest to west-northwest, thus the exposure is an oblique section of the channel intervals. The major erosive down-cutting surfaces show lateral shifting of channelized intervals to the south, here numbering five. Lateral accretion features can be seen in channel 1, and the base of channel 2. Channel 3 also shows thalweg deposits. Channel margin onlap relationships can be seen clearly in chan- input, seismic impedance contrasts between different lithologies, and choice of the dominant seismic wavelet frequency. Seismic impedance contrast can then be calculated using published velocity and density values for the different lithological types in the selected section, and allows the geoscientist to vary the rock values to simulate the petroleum reservoir they are interested in. The geoscientist can also vary the frequency to simulate the depth and/or quality of seismic available to them. Overburden can also be added to simulate real-world situations.

nel 4, and the steep arcuate margin of channel 5 has been interpreted as a rotational slide or slump scar element.

From the detailed bed correlation shown in Figure 6 and combined with the photomontage interpretation shown in Figure 4, a generalized sedimentary input model of the Ainsa II complex was constructed (Fig. 7); Pringle, 2003. The described facies have been grouped into four types: (i) massive sandstone units (and minor discontinuous shales) that were typically $1 \mathrm{~m}$ thick; (ii) medium-bedded sandstones (typically 0.5 $\mathrm{m}$ thick); (iii) shales predominantly shale and thin (typically $0.1 \mathrm{~m}$ ) sandstones and; (iv) shale intervals. Acoustic rock-properties (Fig. 8) have been assigned to 
each of the facies groups, and used for the construction of the synthetic seismic images.

\section{Modeling strategy}

The Ainsa II channel complex is a large-scale outcrop example of stacked channel units. Interpreting the architecture of the stacked channels may be crucial in characterizing analogous reservoirs. The question is, therefore, "how much of the channel architecture could be resolved in typical seismic datasets?" The interpreted 2D sedimentary section has therefore been digitized and used as the input model to generate various forward synthetic seismic 2D images using the GMAplus STRUCT ${ }^{1}$ software program. Positive impedance values are shown as peak (red) colors, while negative impedance values are shown as trough (blue) colors. Rock properties of the four facies groups have been taken from analogous units in reservoirs from the Gulf of Mexico and UK North Sea for comparative purposes. Three sets of parameters have been varied: the seismic impedance contrast, the resolution that could be seen from the input sedimentary model, and different dominant wavelet frequencies (from 26 to $104 \mathrm{~Hz}$ ).

\section{Seismic impedance contrast}

Typical velocity and density values were taken from published data for: (i) massive sandstone units

1. Now GeographiX ${ }^{\mathrm{TM}}$ (and minor discontinuous shales); (ii) medium-bedded, sandstones and shales; (iii) predominantly shale and thin sandstones and lastly; (iv) shale intervals. As the aim was to simulate conventional seismic information through reservoirs with comparable seismic impedance values, velocity values from three producing reservoirs were used. The three producing reservoirs were the Forties Field, a Tertiary North Sea (UKCS) reservoir; the Magnus Field, a Jurassic, North Sea (UKCS) reservoir; and the Mars Field, a Plio-Pleistocene, Gulf of Mexico reservoir. Values for the three reservoirs were obtained from published data from Jager et al. (1997), Partington et al. (1993), and Chapin et al. (1996), respectively; these values are detailed in Figure 8.

\section{Resolution of the sedimentary model}

The channel complex model incorporates different scales of sedimentary complexity which is used to test how much can be resolved from the different frequency, synthetic seismic 2D images. Future work could include forward modeling the synthetic seismic output and comparing it with the sedimentary input model. 


\section{Wavelet frequency}

Four dominant Ricker wavelet frequencies were chosen for this study: $26 \mathrm{~Hz}$ wavelet, typical of seismic datasets from deeper buried reservoirs; $52 \mathrm{~Hz}$ wavelet, typical of industry higher frequency shallow seismic datasets; $78 \mathrm{~Hz}$ wavelet, selected as current, cuttingedge seismic acquisition; and $104 \mathrm{~Hz}$ wavelet, sometimes acquired for investigating the near-surface

\section{Results}

Synthetic Seismic Images generated by GMAplus STRUCT ${ }^{\mathrm{TM}}$ are now detailed. Note that the images have been compressed laterally and exaggerated horizontally to assist the potential seismic interpreter, consistent with present high-resolution seismic studies which is advocated and justified from these results to gain sub-seismic resolution.

Low Resolution Seismic Images $(26 \mathrm{~Hz})$ are shown in Figures 9-11. The lowest frequency wavelets chosen $(26 \mathrm{~Hz})$ typically are used for imaging deep reservoir targets, such as the Jurassic turbidite reservoirs in the North Sea. For all three reservoir scenarios, an extra broad positive amplitude reflection event is present in the middle part of the section, compared to the background values, with the slumped interval to the left of the section unimaged. The acoustic rock properties from the three different reservoirs do, however, show subtle differences. The lowest impedance contrast between heterogeneities within the channel complex placement of oil rigs. The GMAplus STRUCT ${ }^{\mathrm{TM}}$ software program displays both the seismic image and the seismic traces overlain on the time-converted seismic model. Traces are spaced at $12.5 \mathrm{~m}$, equivalent to typical inline seismic section. Vertical incidence, zerooffset rays were chosen to avoid the complexities of dip move-out and migration, which commonly occur in standard, seismic Common Mid-Point (CMP) data. comes from the Jurassic North Sea analog. At the low resolution seismic frequency, the thickening of the top reflector and the slump scar feature would indicate the likely presence of complex reservoir architecture. The acoustic properties used from the two Tertiary analogues show a greater impedance contrast between intra-channel complex units, and the seismic images suggest a clearer lens-like shape to the reservoir.

High Resolution Seismic Images $(52 \mathrm{~Hz})$ are shown in Figures 9-11. Higher frequencies (e.g. $52 \mathrm{~Hz}$ ) are commonly used for imaging higher level reservoir targets. Using this frequency, a greater amount of reservoir architecture can be interpreted. As well as the obvious positive amplitude event in the middle part of the section, some heterogeneities are resolved at this interval. The image suggests there are at least three compartments to the channel complex: one corresponding to channel units 1,2 , and 3 ; one to channel unit 4 ; and one to the slump scar and infill, channel unit 5. 
Very High Resolution Seismic Images $(78 \mathrm{~Hz}$ ) are shown in Figures 9-11. Current shallow level, seismic targets are imaged up to $78 \mathrm{~Hz}$, the third frequency chosen to generate seismic sections. Some additional internal channel heterogeneity can be resolved using this frequency, especially channels $2-4$, and channel 4 is successfully resolved. The geophysical interpretation using this frequency data would be close to the digitized input sedimentary model.

Possible future seismic resolution Images (104 $\mathrm{Hz}$ ) are also shown in Figures 9-11. With this level of

\section{Discussion}

The results detailed above suggest that outcrops of turbidite channel complexes may be utilized for generating synthetic seismic images that can then be used as analogs. A 2D synthetic seismic section generated from a low frequency $(26 \mathrm{~Hz})$ wavelet would most probably give a geophysical interpretation that would miss the sedimentary heterogeneity likely present within a turbidite channel-complex and crucial for determining barriers to fluid flow. These low frequencies are those typically used in deep Jurassic targets in the North Sea. Using a $52 \mathrm{~Hz}$ frequency however, typically found in shallow level Tertiary targets, a much improved geophysical interpretation could be achieved that would resolve the major architectural elements of a stacked, channel sequence. However, the relatively thin intervals that could potentially form the barriers to fluid flow would not be imaged. The nature of channel stack- seismic resolution, a geophysical interpretation of the seismic section could be close to the input sedimentary model. In the next decade or so, frequencies as high as $100 \mathrm{~Hz}$ may be used.

The differing impedance values for the three chosen reservoir examples had little effect on the interpretation at the high signal/noise ratios used. Although some of the internal sedimentary architecture is resolved, the impedance values from the Jurassic North Sea reservoir analog yield the highest amplitudes from the generated synthetic sections.

ing, erosional contacts or mud drapes would, most likely, not be imaged at this frequency. At $78 \mathrm{~Hz}$, which is typical of high frequency seismic acquisition/processing, a geophysical interpretation close to the actual input sedimentary model could be achieved.

From these results, future improvements in seismic resolution would be extremely valuable for the interpretation of analogous channel-complex reservoirs. Further work should generate fully 3D cubes to be relevant to modern, seismic industry data and be re-run with differing quantities of fluids to be more realistic. Overburden should also be added to make the seismic models more comparable to producing reservoirs. Forward modeling of the synthetic seismic images could also be undertaken to compare and contrast the similarities between the synthetic geology and the original 
geological interpretation that was the basis of the input model.

\section{Conclusion}

Spectacularly exposed, large-scale outcrops can be forward seismic modeled to compare the high resolution of geo-scientific data from outcrops to the relatively lower resolution from seismic data. Seismic model sections generated from typical low frequency wavelets will not be able to resolve the typical sedimen-

\section{Acknowledgments}

Peter Olden gave guidance on the use of GMA. Robin Westerman and Leon Barens related the convolutional model used by GMA to the wider context of wavefield modeling and of surface seismic acquisition and processing practice. The Heriot-Watt University Genetic Units Project (GUP) and GEOTipe Project,

\section{References}

Batzle, M. and M.H. Gardner, 2000, Lithology and fluids: seismic models of the Brushy Canyon Formation, West Texas, in A.H. Bouma and C.G. Stone, eds., Fine-Grained Turbidite Systems: AAPG Memoirs 72, p. $127-142$.

Chapin, M.A., G.M. Tiller, and M.J. Mahaffie, M.J, 1996, 3$\mathrm{D}$ architecture modeling using high-resolution seismic data and sparse well control: examples from the Mars "Pink" Reservoir, Mississippi Canyon area, Gulf of tary complexity observed in channel outcrop exposures that may be crucial for potential hydrocarbon recovery. The generated, high-frequency sections allow interpretations that almost replicate the input sedimentary models.

both funded by petroleum-industry consortia, are acknowledged for financial support for J. Pringle for this study and Will Schweller and Chuck Stelting for attendance on a Chevron internal fieldtrip to the Ainsa area. Nautilus UK Ltd is acknowledged for the use of drafted materials.

Mexico, in P. Weimer and T.L. Davis, eds., Applications of 3-D seismic data to exploration and production: AAPG Studies in Geology No. 42, AAPG/SEG Joint Publication, Tulsa, Oklahoma, 5, p. 123-131.

Clark, J.D, 1995, Detailed section across the Ainsa II Channel complex, south central Pyrenees, Spain, in K.T. Pickering, et al., eds., Atlas of Deep Water Environments: Architectural Style in Turbidite Systems: Chapman \& Hall, London, p. 139-144. 
Coleman, J.L., F.C. Sheppard III, and T.K. Jones, 2000, Seismic resolution of submarine channel architecture as indicated by outcrop analogues, in A.H. Bouma and C.G. Stone, eds., Fine-Grained Turbidite Systems: AAPG Memoir 72, p. 119-126.

Jager D.H., et al., 1997, Variety of turbidite deposits within the Forties Fan: examples from the Nelson Field, in C.D. Oakman, J.H. Martin, and P.W.M. Corbett, eds., Cores from the NW European Hydrocarbon Province: an illustration of geological applications from exploration to development: Geological Society of London, $\mathrm{p}$. 175-180.

Larue, D., 2004, Outcrop and waterflood simulation modeling of the 100-foot Channel Complex, Texas and the Ainsa II Channel Complex, Spain: Analogs to multistory and multilateral channelized slope reservoirs, in M. Gramer, P.M. Harris, G.P. Eberli, eds., Integration of Outcrop and Modern Analogs in Reservoir Modeling: AAPG Memoir 80, p. 337-364.

Mutti, E., and W.R. Normark, 1987, Comparing examples of Modern and Ancient Turbidite Systems: Problems and Concepts, in J.K. Leggett, and G.G. Zuffa, eds., Deep Water Clastic Deposits: Models and Case Histories: Graham \& Trotman, London, p. 1-38.

Mutti, E., M. Seguret, and M. Sgavetti, 1989, Sedimentation and Deformation in the Tertiary Sequences of the Southern Pyrenees: AAPG Mediterranean Basins Conference Guidebook Fieldtrip No. 7, Nice, Special
Publication of the Institute of Geology, University of Parma.

Partington M.A.., P. Copestake, B.C. Mitchener, and J.R. Underhill, 1993, Genetic sequence stratigraphy for the North Sea Late Jurassic and Early Cretaceous: distribution and prediction of Kimmeridgian-Late Ryazanian reservoirs in the North Sea and adjacent areas, in J.R. Parker, ed., Petroleum Geology of Northwest Europe: Proceedings of the 4th Conference, The Geological Society, London, 1, p. 347-370.

Pickering, K.T., and J. Corregidor, 2000, 3D reservoir scale study of the Eocene confined submarine fans, South Central Spanish Pyrenees: 20th Annual Bob F. Perkins GCSSEPM Foundation Research Conference, p. 776781.

Pringle, J.K., J.D. Clark, A.R. Westerman, D.A. Stanbrook, A.R. Gardiner, and B.E.F. Morgan, 2001, Virtual Outcrops: 3-D reservoir analogues, in L. Ailleres, and T. Rawling, eds., Animations in Geology: Journal of the Virtual Explorer, p. 3.

Pringle, J.K., 2003, Integrated techniques for the acquisition and visualisation of $3 \mathrm{D}$ meso- to macro-scale sedimentary architectures of petroleum reservoir outcrop analogues: Petroleum Engineering Institute, HeriotWatt University unpublished $\mathrm{PhD}$ dissertation, $326 \mathrm{p}$.

Schwab, A.M., B.T. Cronin, and H. Ferreira, 2007, Seismic expression of channel outcrops: offset stacked versus amalgamated channel systems: Marine and Petroleum Geology, 24, p. 504-514. 


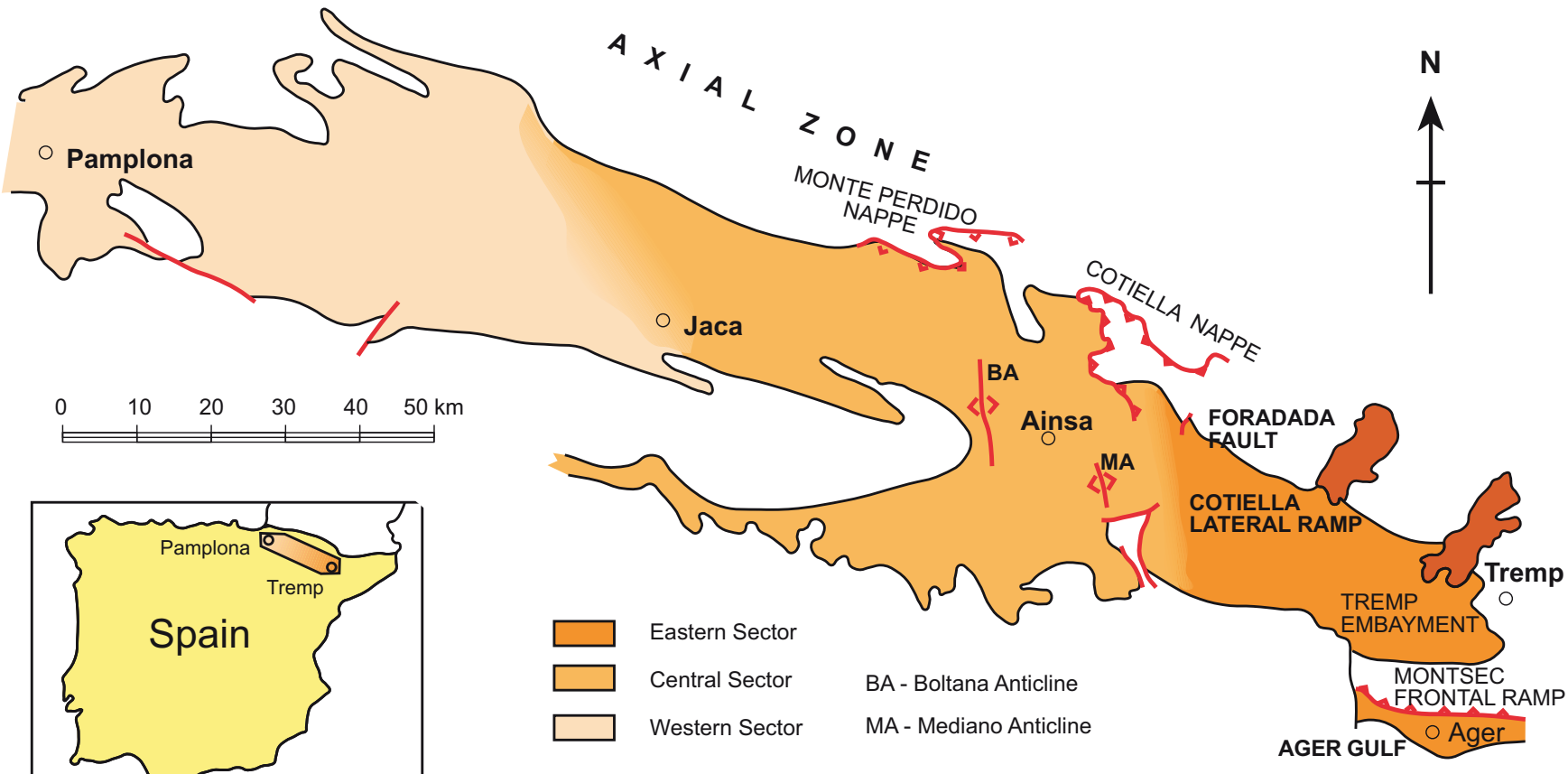

Figure 1. Map showing the main structural elements and palaeogeographic sectors of the Eocene Tremp-Pamplona Basin (from Mutti et al., 1989). 


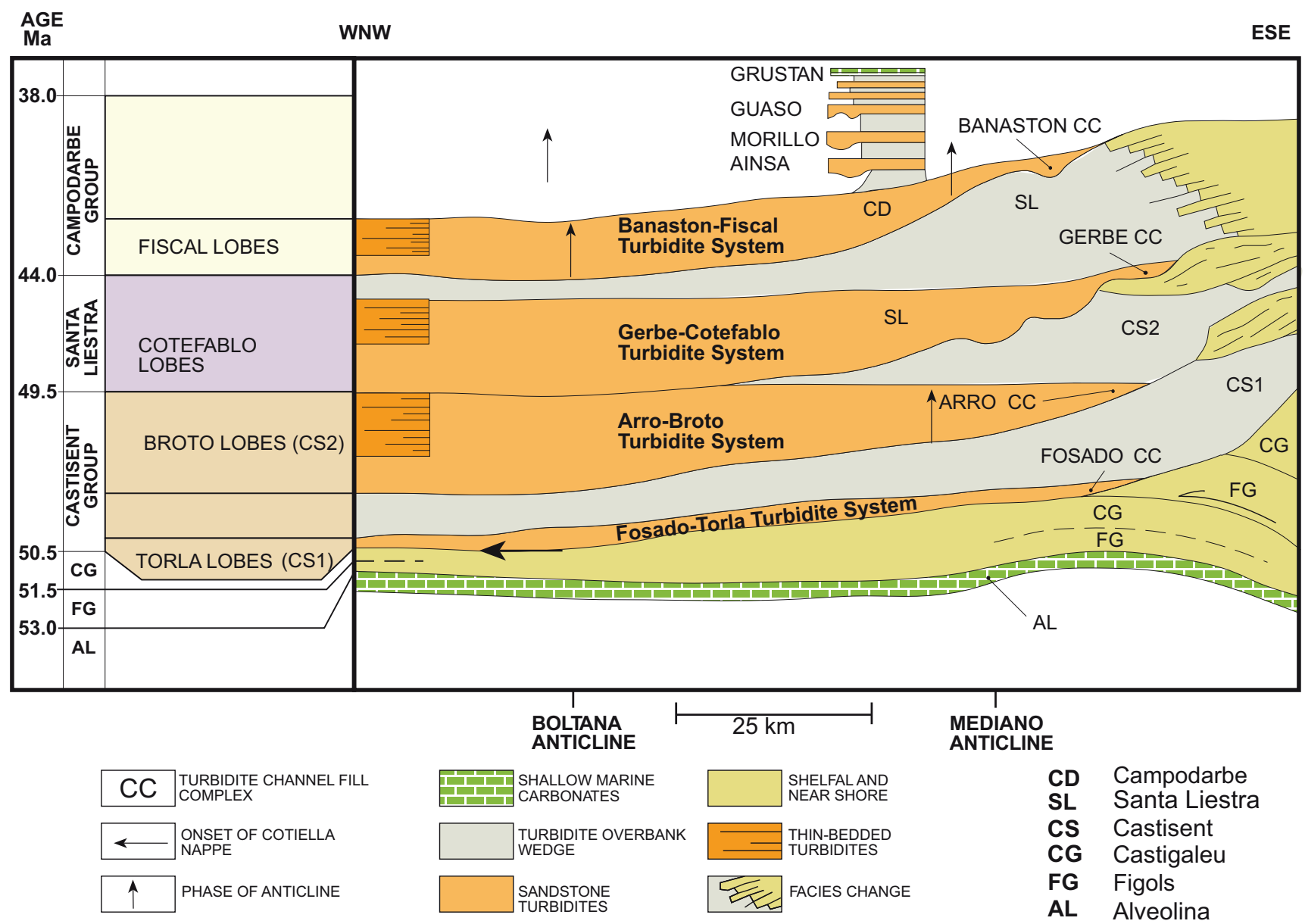

Figure 2. Paleoenvironments of the Central Sector of the Tremp-Pamplona Basin (after Mutti et al., 1989). 


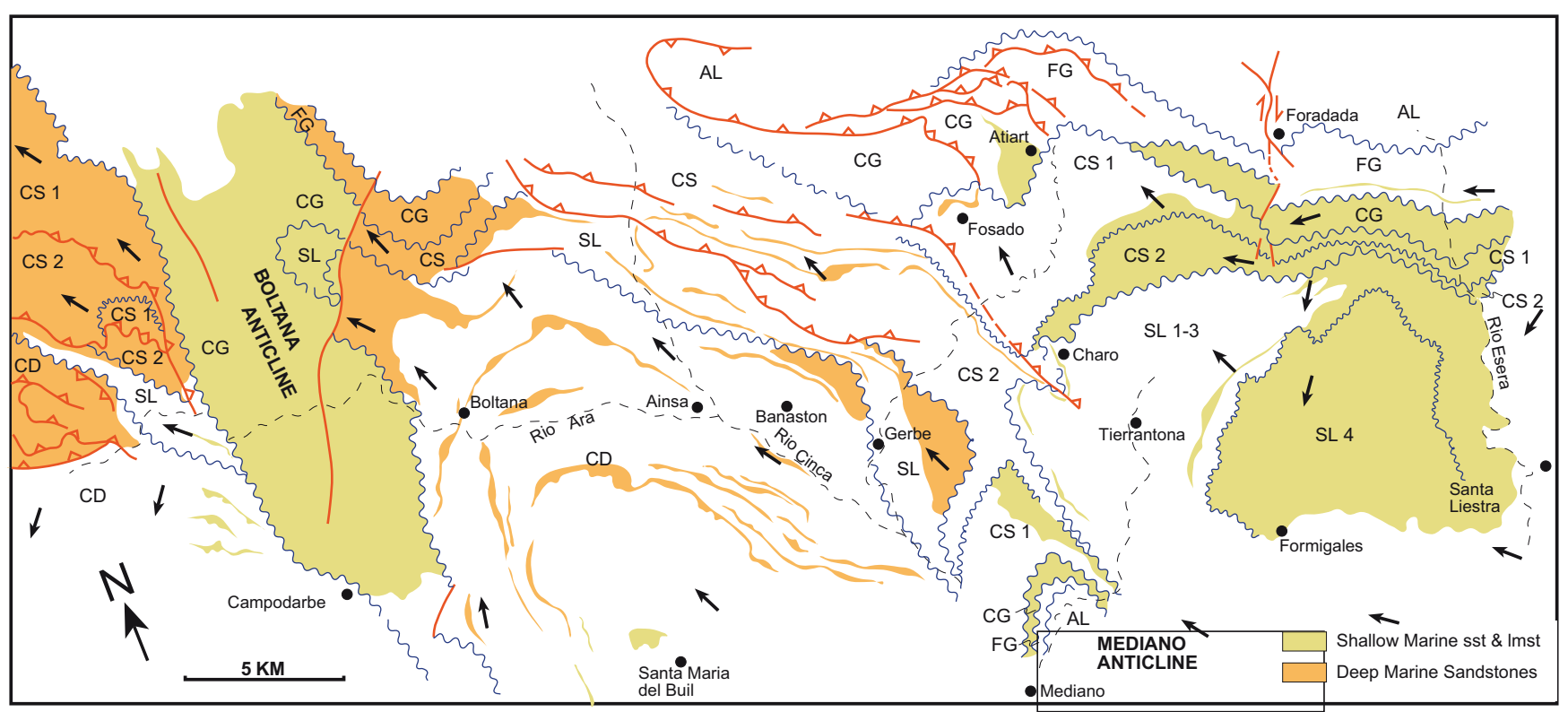

Figure 3. Stratigraphic sketch of the Eocene in the Tremp-Pamplonia basin. The Ainsa channel complex is found in the Upper Campodarbe Group systems (from Mutti et al, 1989). 

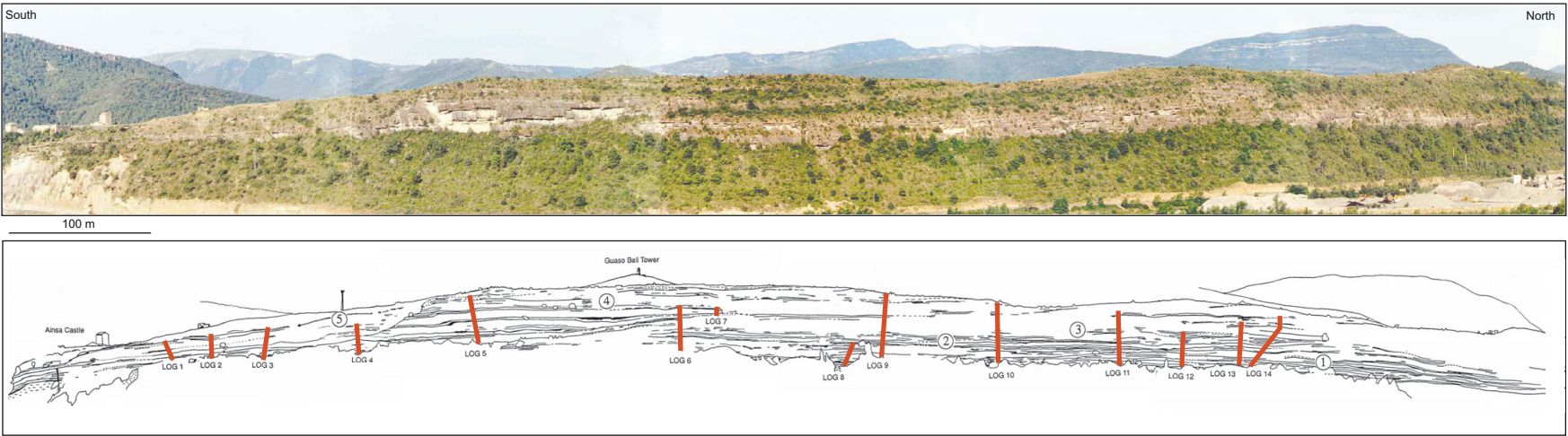

Figure 4. Photomontage and interpretation of the Ainsa II channel complex viewed from across the Rio Cinca. Sedimentary logs through the section are shown in red labeled 1 - 14. The lateral southward shifting of channel bodies can be clearly seen in the photomontage. 


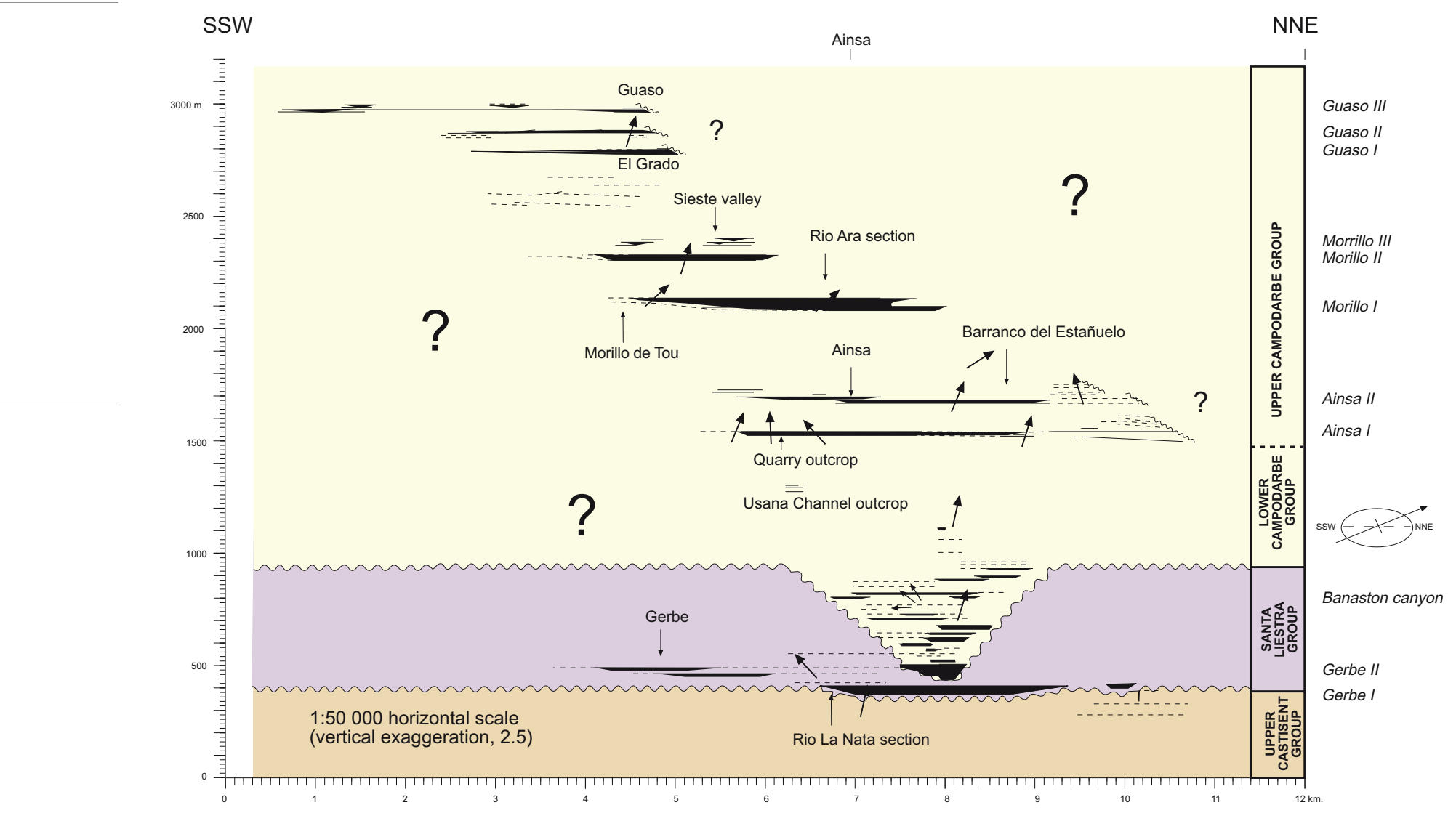

Figure 5. Restored section of the Ainsa basin (based on interpretation from an aerial photograph) showing the vertical distribution of the channel-levee complexes. Paleocurrent arrows are orientated with respect to the orientation of the section (SSW-NNE), i.e., vertical arrows indicate paleocurrent directions are towards the west-northwest (Clark, 1995). Regional unconformities are those mapped by Mutti et al., 1989. 


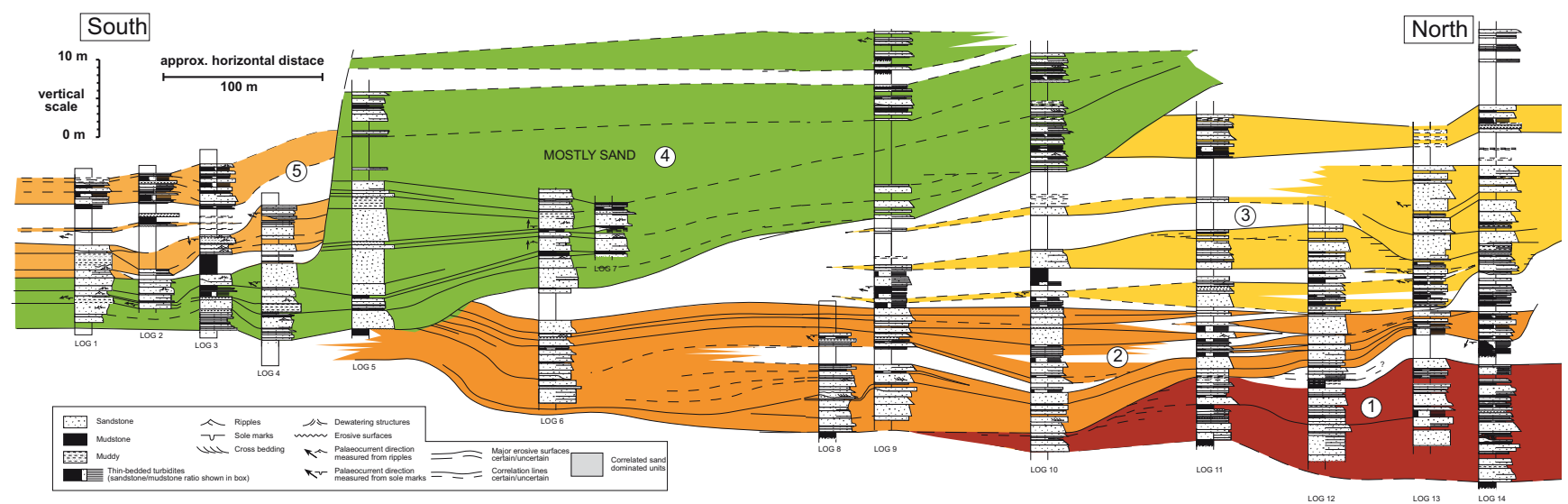

Figure 6. Bed correlation of the Ainsa II channel showing the five stacked channel elements numbered 1-5 (adapted from Clark, 1995). See Figure 4 for log locations. 


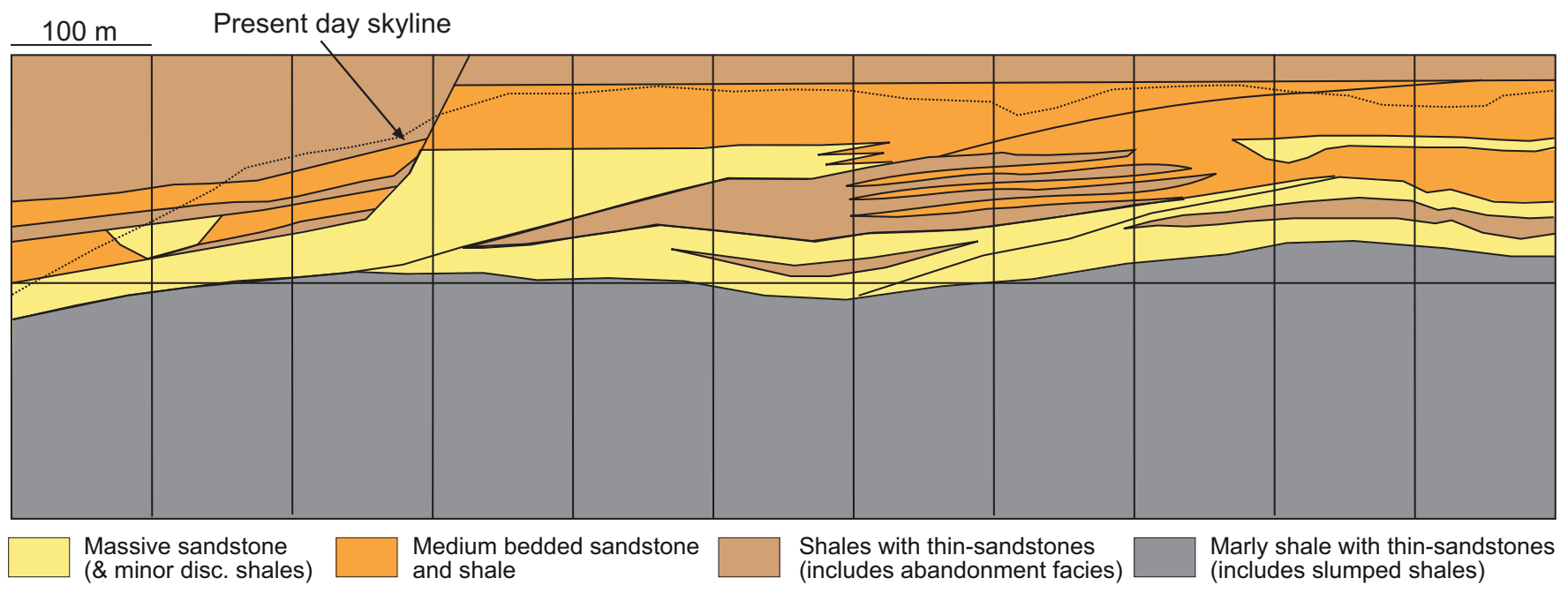

Figure 7. Sedimentary interpretation of the Ainsa II channel complex from a combination of photomontage interpretation, sedimentary log correlations, and walking-out of key stratigraphic surfaces. 


\begin{tabular}{|l|r|r|l|}
\hline \multicolumn{2}{|l|}{ Gulf of Mexico Parameters } & & \\
\hline & & & \\
\hline & $\begin{array}{l}\text { Veloci ty } \\
(\mathrm{m} / \mathrm{s})\end{array}$ & $\begin{array}{l}\text { Densi ty } \\
(\mathrm{g} / \mathrm{cc})\end{array}$ & $\begin{array}{l}\text { Impedance } \\
\left(\mathrm{kg} \mathrm{m}^{-2} \mathrm{~s}^{-1}\right)\end{array}$ \\
\hline Massive sandstone & 3672 & 2.08 & $7628 \times 10^{3}$ \\
\hline Shale and marl & 2650 & 2.25 & $5692 \times 10^{3}$ \\
\hline $\begin{array}{c}\text { Medium bedded } \\
\text { sandstones \& shales }\end{array}$ & 3387 & 2.13 & $7214 \times 10^{3}$ \\
\hline $\begin{array}{c}\text { Thin bedded } \\
\text { sandstones \& shales }\end{array}$ & 2900 & 2.19 & $6351 \times 10^{3}$ \\
\hline
\end{tabular}

\begin{tabular}{|l|r|r|l|}
\hline \multicolumn{2}{|l|}{ Jurassic North Sea Parameters } & & \\
\hline & $\begin{array}{l}\text { Veloci ty } \\
(\mathrm{m} / \mathrm{s})\end{array}$ & $\begin{array}{l}\text { Densi ty } \\
(\mathrm{g} / \mathrm{cc})\end{array}$ & $\begin{array}{l}\text { Impedance } \\
\left(\mathrm{kg} \mathrm{m}^{-2} \mathrm{~s}^{-1}\right)\end{array}$ \\
\hline Massive sandstone & 4233 & 2.43 & $10286 \times 10^{3}$ \\
\hline \begin{tabular}{l} 
Shale and marl \\
\hline $\begin{array}{l}\text { Medium bedded } \\
\text { sandstones \& shales }\end{array}$
\end{tabular} & 3110 & 2.53 & $7868 \times 10^{3}$ \\
\hline $\begin{array}{c}\text { Thin bedded } \\
\text { sandstones \& shales }\end{array}$ & 3484 & 2.48 & $9568 \times 10^{3}$ \\
\hline
\end{tabular}

Figure 8. Seismic parameters used in this study.

\begin{tabular}{|l|r|r|l|}
\hline \multicolumn{2}{|l|}{ Tertiary North Sea Parameters } & & \\
\hline & $\begin{array}{l}\text { Velocity } \\
(\mathrm{m} / \mathrm{s})\end{array}$ & $\begin{array}{l}\text { Density } \\
(\mathrm{g} / \mathrm{cc})\end{array}$ & $\begin{array}{l}\text { Impedance } \\
\left(\mathrm{kg} \mathrm{m}^{-2} \mathrm{~s}^{-1}\right)\end{array}$ \\
\hline Massive sandstone & 3208 & 2.17 & $6961 \times 10^{3}$ \\
\hline \begin{tabular}{l} 
Shale and marl \\
\hline $\begin{array}{l}\text { Medium bedded } \\
\text { sandstones \& shales }\end{array}$
\end{tabular} & 2498 & 2.35 & $5870 \times 10^{3}$ \\
\hline $\begin{array}{c}\text { Thin bedded } \\
\text { sandstones \& shales }\end{array}$ & 2703 & 2.27 & $6590 \times 10^{3}$ \\
\hline
\end{tabular}


TOC

Start

Author

Search

Help
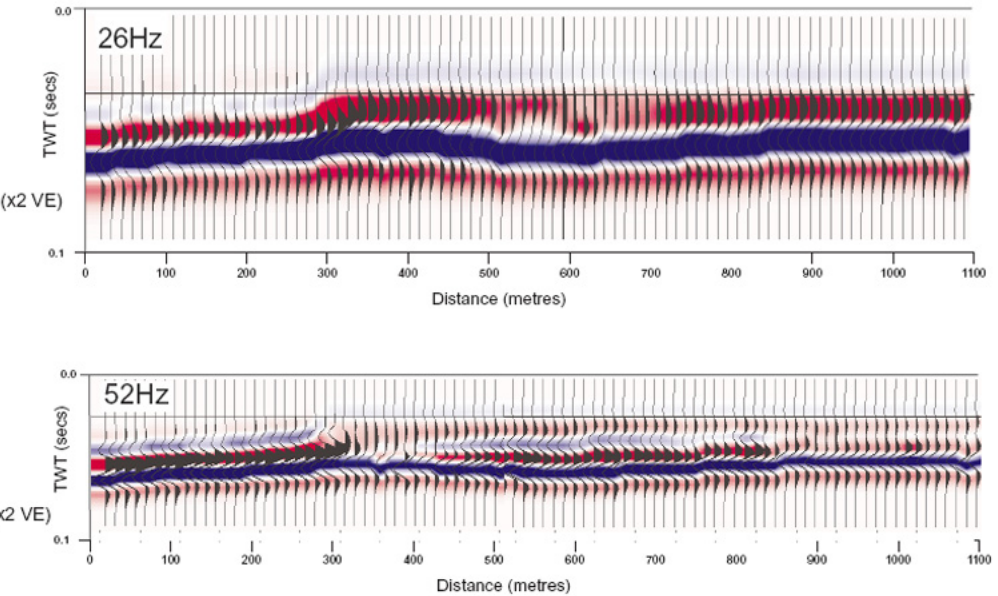

( $\mathrm{x} 2 \mathrm{VE})$

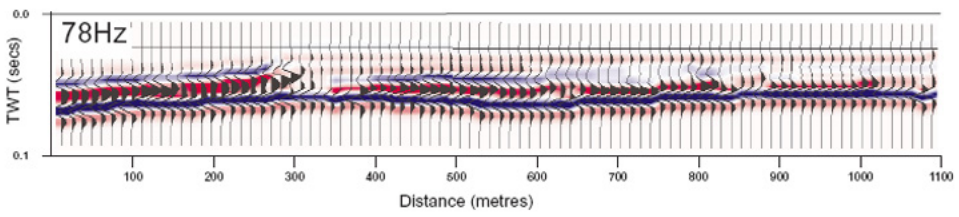

$(\times 2$ VE

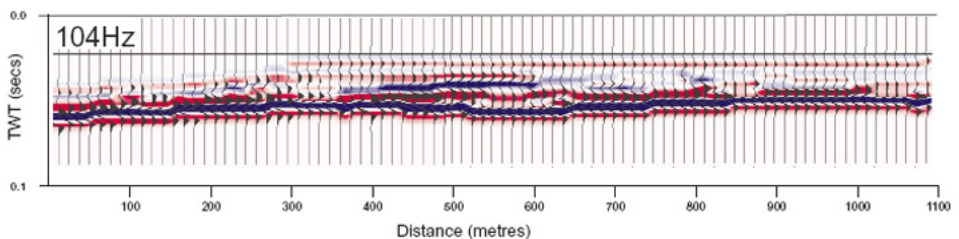

Figure 9. Plio-Pleistocene, Gulf of Mexico analog output from GMAplus STRUCTTM software showing $26 \mathrm{~Hz}, 52 \mathrm{~Hz}$, 78 , and $104 \mathrm{~Hz}$ frequencies, with both $\mathrm{B}-\mathrm{W}-\mathrm{R}$ color impedance and wiggle trace wavelets respectively (see text for description and discussion). Note wavelet sections have the input model shown behind as solid colors. 
TOC

Start

Author

Search

Help
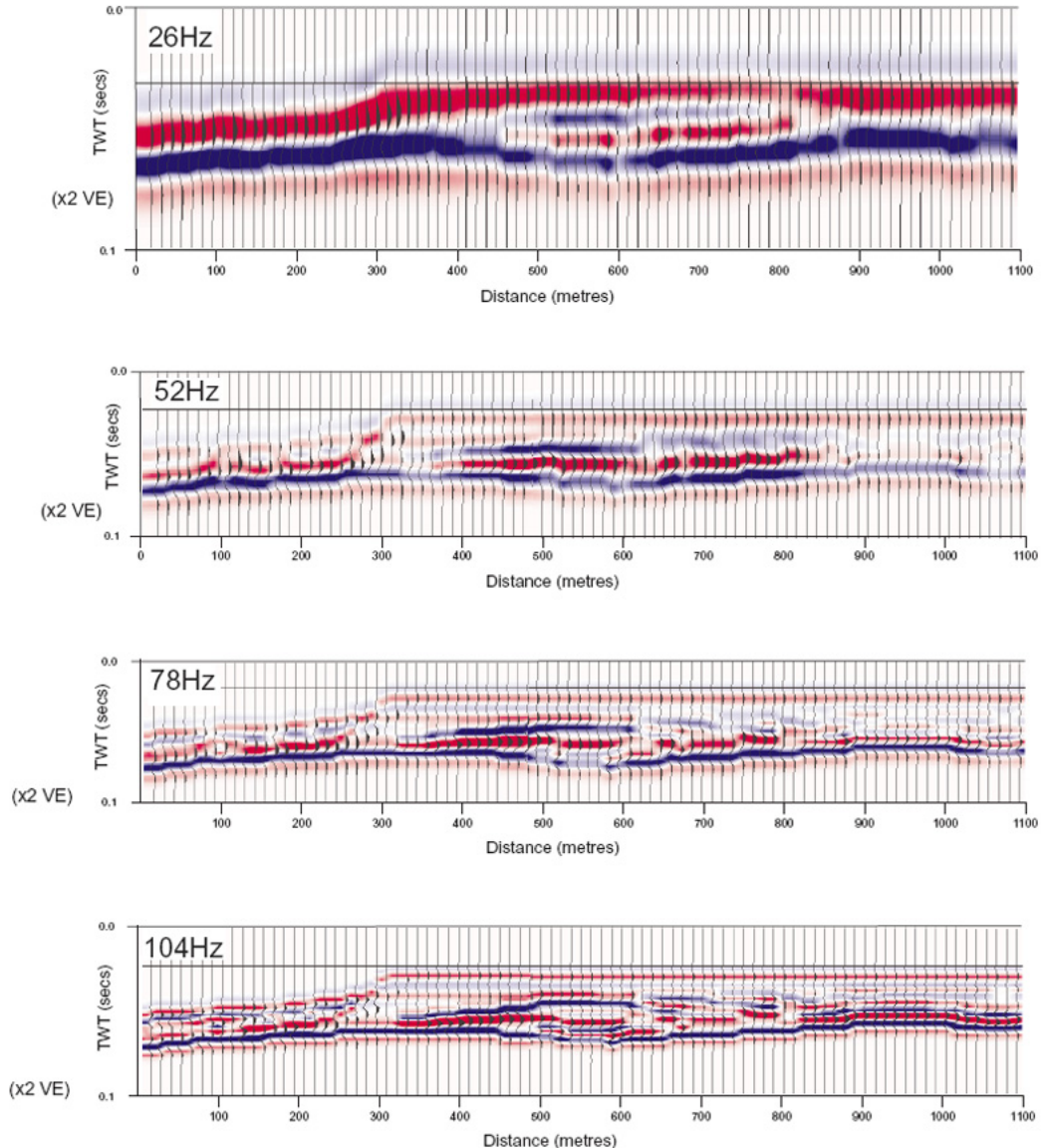

Figure 10. Jurassic, UK North Sea analogue output from GMAplus STRUCT ${ }^{\mathrm{TM}}$ software showing $26 \mathrm{~Hz}, 52 \mathrm{~Hz}, 78$, and $104 \mathrm{~Hz}$ frequencies, with both B-W-R color impedance and wiggle trace wavelets respectively (see text for description and discussion). Note wavelet sections have input model shown behind as solid colors. 
TOC

Start

Author

Search

Help

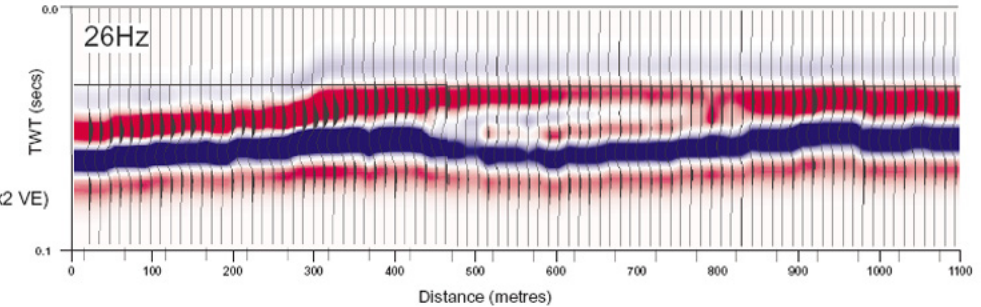

(X2 VE)

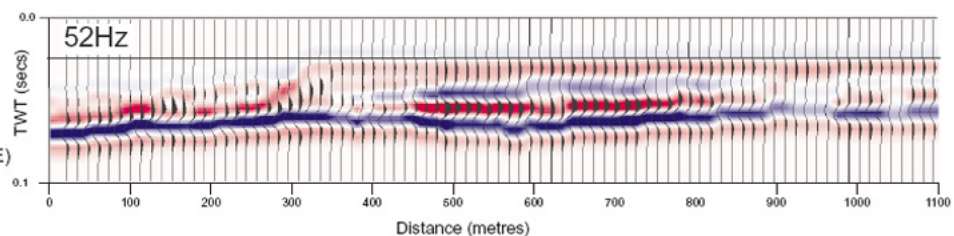

( $\mathrm{x} 2 \mathrm{VE})$

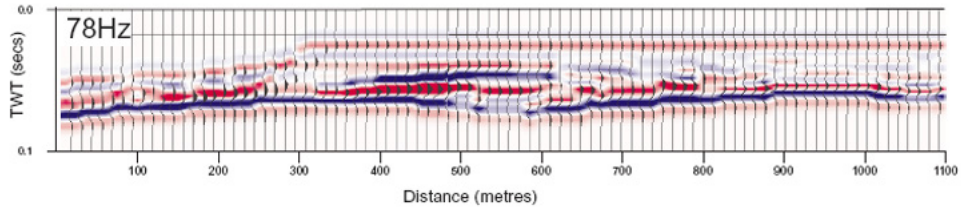

(x2 VE)

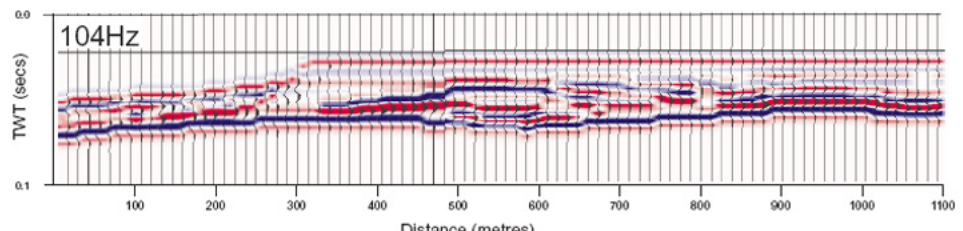

Figure 11. Tertiary, UK North Sea analogue output from GMAplus STRUCT ${ }^{\mathrm{TM}}$ showing $26 \mathrm{~Hz}, 52 \mathrm{~Hz}, 78$, and $104 \mathrm{~Hz}$ frequencies, with both B-W-R color impedance and wiggle trace wavelets respectively (see text for description and discussion). Note wavelet sections have input model shown behind as solid colors. 